\title{
Coexistence of Pulmonary tuberculosis and lung cancer
}

Sandeep Mahajan, ${ }^{1}$ Vijay Gotwal, ${ }^{2}$ Neeraj Lata, ${ }^{3 *}$ Nisanth. PS. ${ }^{2}$

Assistant Professor, Department of chest and Tuberculosis ${ }^{1}$ Junior Resident, Department of chest and Tuberculosis, ${ }^{2}$

Senior Resident, Department of Pediatrics, ${ }^{3}$

Government Medical College, Amritsar

\section{DOI Name}

http://dx.doi.org/10.3126/jaim.v6i1.18313

\section{Keywords}

Lung carcinoma,Tuberculosis

\section{Citation}

Sandeep Mahajan, Vijay Gotwal, Neeraj Lata, Nisanth. Coexistence of Pulmonary tuberculosis and lung cancer. Journal of Advances in Internal Medicine 2017;06(01):11-13.

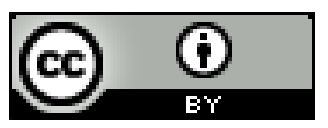

This work is licensed under a Creative Commons Attribution 3.0 Unported License.

\begin{abstract}
Pulmonary Tuberculosis can co-exist with lung malignancy masking the underlying disorder leading to delay in diagnosis and management. Here we present an interesting case of a 72 year old female who on initial presentation was diagnosed with tuberculosisbut later developed plural effusion during treatment and on investigation was found to have an underlying lung malignancy.

Introduction:Pulmonary Tuberculosis and lung carcinoma are the two co morbidities that have been shown in many studies to coexist. Many of Signs and symptoms of Pulmonary Tuberculosis mimics lung carcinoma and coexistence increases mortality and morbidity.So we are presenting a case which had pulmonary Tuberculosis and later developed carcinoma lung.
\end{abstract}

\section{CASE}

History: 72 year old female presented with breathlessness and cough for 4 months. She had history of decreased appetite. She is a known case of Diabetes mellitus and hypertension and is on medication for the same. No family history of similar complaints or chronic illness. Past history of hospitalisation in our hospital 2 months back for similar complaints for two weeks.H/o of intake of Antitubercular medication for last two months4 drugs HRZE (DOTS regime).

Physical examination revealed pallor.There was no icterus, cyanosis, clubbing and bony tenderness.

Heart rate- 90/min, Respiratory rate 32/min.Respiratory distress present.use of accessory muscles of respiration present.

Chest examination:Right side of chest appeared prominent. Breath sounds were decreased on right side of chest in mammary, infraaxillary, infrascapular area Bronchial breath sounds and whispering pectoriloquy were present on right mammary area and axilllary area.

Systemic examination was normal.

On Investigations:Patient had anemia with leucocytosis. Erythrocyte sedimentation rate was raised (64).Liver function tests and Renal function tests were within normal limits.

Chest Xray (Fig:1,2)of patient showed consolidation initially which had progressed to pleural effusion in one month.

Figure1: Chest Xray

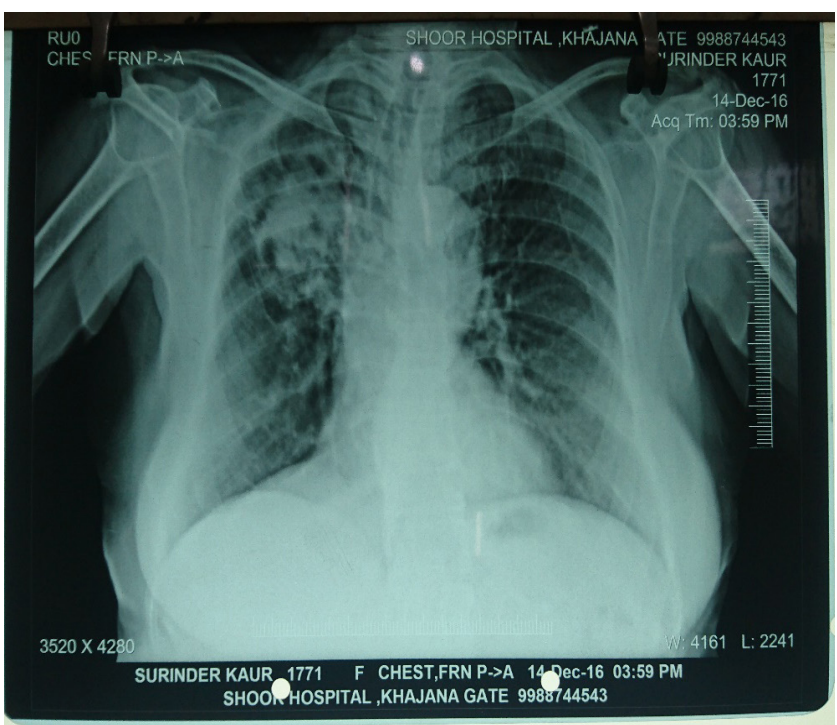

* Corresponding author

Dr Neeraj Lata.

Senior Resident. Department of Pediatrics.

Government Medical College, Amritsar

neerajlatavijay@gmail.com 
Figure2 ChestXray(done after one month)

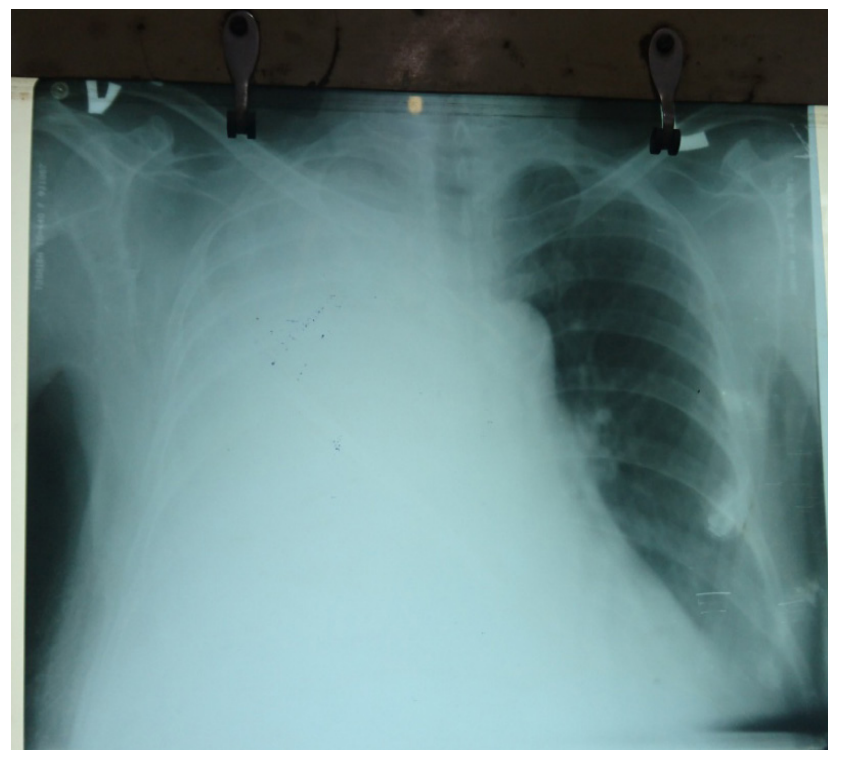

CT Scan (Fig :3,4) showed consolidative changes involving right upper lobe with areas of breakdown and soft tissue attenuation within the cavity, with adjacent consolidative changes involving right upper lobe.

Figure3:CTscan Chest

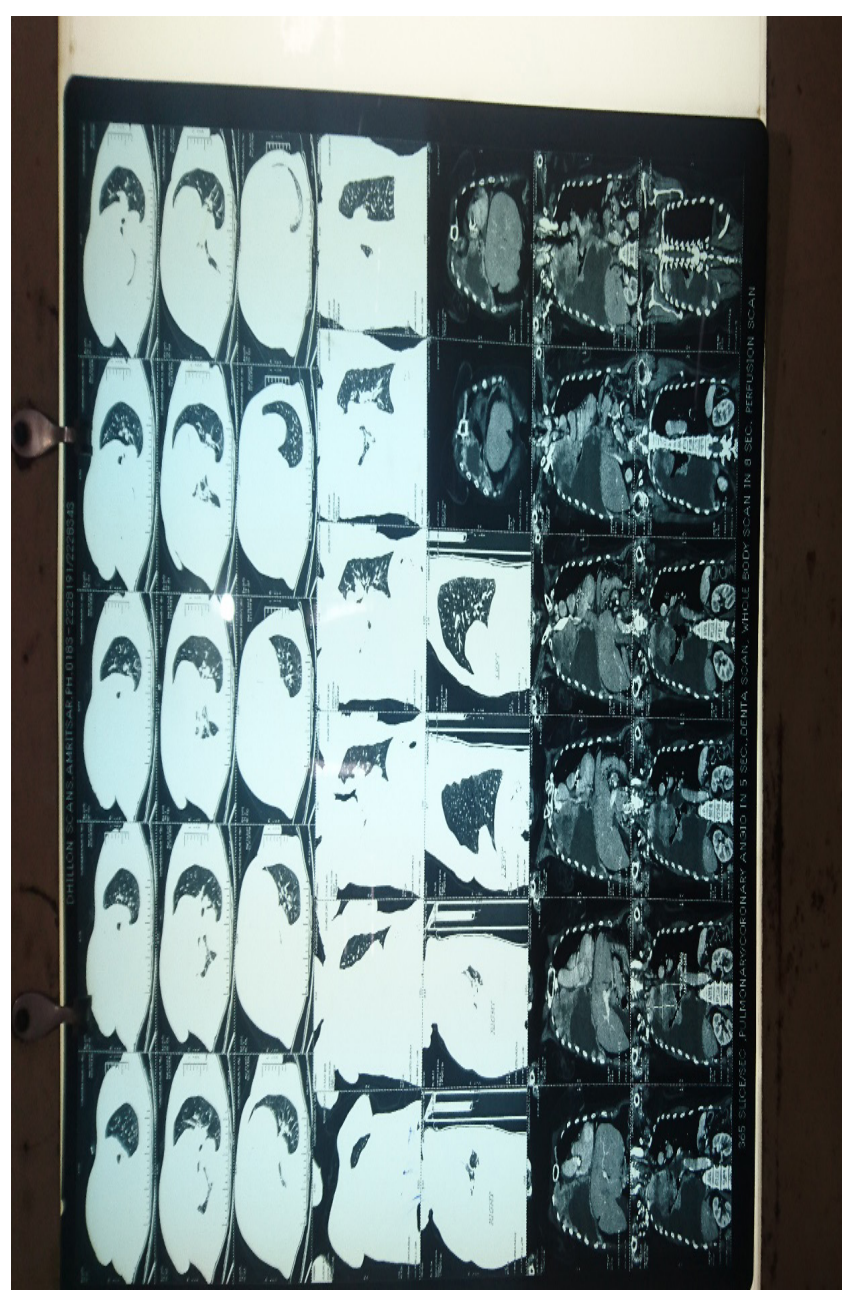

Figure4 CT scan Chest

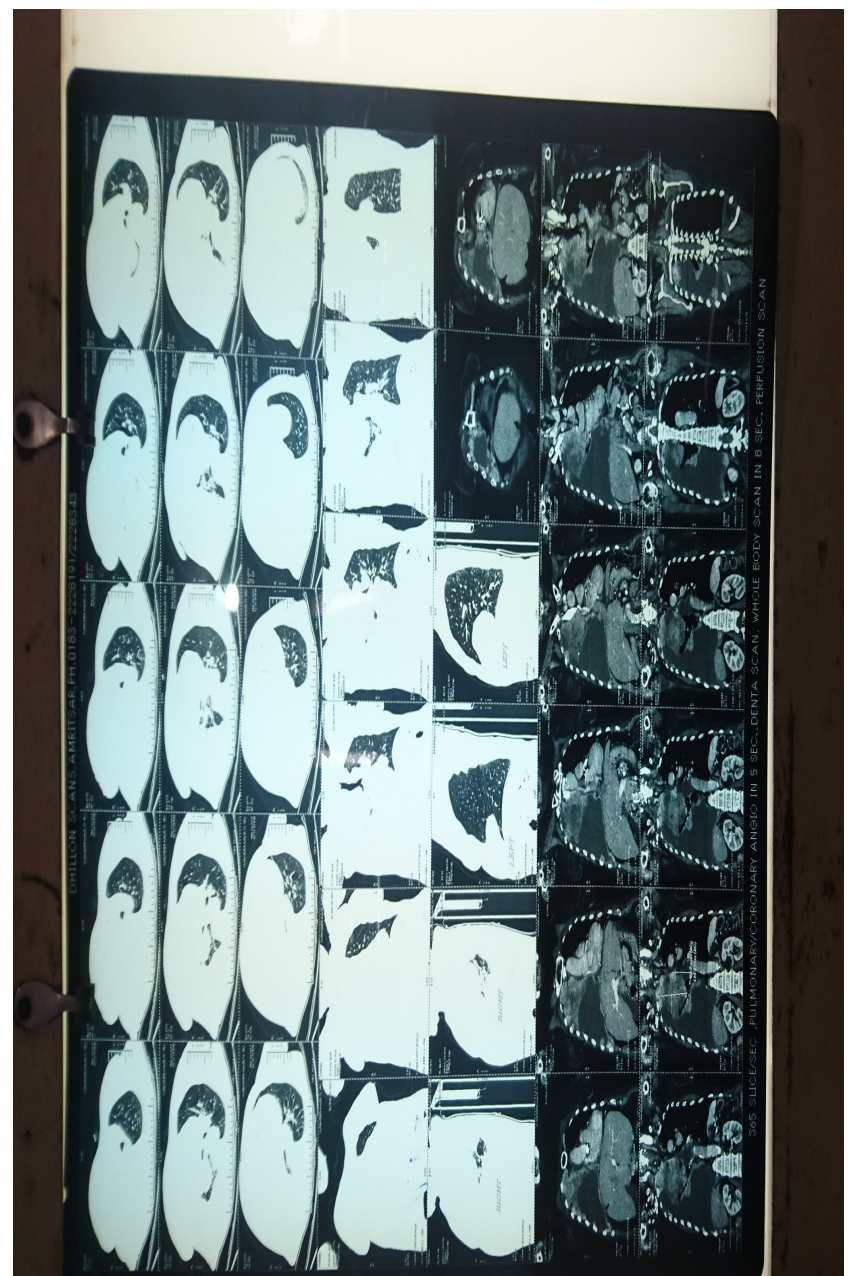

Patient was given broad spectrum antibiotics. Bronchoalveolar lavage was done which had shown Acid fast bacilli positivity.On this basis Antitubercular treatment (4drugs HRZE)was started. But symptoms of patient worsened in form that she developed breathing difficulty and loss of appetite.Repeat Xray showed right sided moderate pleural effusion.Ultrasound chest showed moderate pleural effusion on right side and minimal on left side.CTscan with CTguided biopsy was done which showed Mitotic mass in right upper lobe showing mediastinal invasion with moderate degree of right sided pleural effusion ,pleural deposits .

Cytology showed High grade malignant spindly cell sarcoma/high grade undifferentiated pleomorphic sarcoma. Antitubercular treatment was continued and Patient was referred to higher center for treatment of lung carcinoma.

\section{DISCUSSION:}

Lung cancer, also known as lung carcinoma, ${ }^{[1]}$ is a malignant lung tumor characterized by uncontrolled cell growth in tissues of the lung. ${ }^{[2]}$ Worldwide in 2012, lung cancer occurred in 1.8 
million people and resulted in 1.6 million deaths. ${ }^{[3]}$ The most common age at diagnosis is 70 years. In 2015, there were an estimated 10.4 million new (incident) TB cases worldwide, of which 5.9 million (56\%) were among men, 3.5 million (34\%) among women and 1.0 million (10\%) among children. ${ }^{4}$

The simultaneous or sequential occurrence of pulmonary tuberculosis and Lung carcinoma in the same patient has been reported in various case series and case-control studies. ${ }^{(5-10)}$

It has been suggested that inflammation and pulmonary fibrosis caused by tuberculosis can induce genetic damage, which can increase lung carcinoma risk. ${ }^{(11-13)}$ The increased occurrence of Lung carcinoma in patients with tuberculosis can also be related to infection-induced immunosuppression. ${ }^{14}$ Cancerinduced or chemotherapy-induced immunosuppression can also lead to increased rates of tuberculosis reactivation in patients with solid tumors. ${ }^{15}$

\section{BIBLIOGRAPHY}

1. «Lung Carcinoma: Tumors of the Lungs». Merck Manual Professional Edition, Online edition. Retrieved 15 August 2007.

2. 2 "Non-Small Cell Lung Cancer Treatment -Patient Version $\left(\mathrm{PDQ}^{\circledR}\right)$ ". $\mathrm{NCl}$. May 12, 2015. Retrieved 5 March 2016.

3. World Cancer Report 2014. World Health Organization. 2014. pp. Chapter 5.1. ISBN 92-832-0429-8.

4. Global tuberculosis report ;2016:WHO

5. Brenner AV, Wang Z, Kleinerman RA, Wang L, Zhang S, Metayer $C$, et al. Previous pulmonary diseases and risk of lung cancer in Gansu Province, China. Int J Epidemiol. 2001;30(1):118-24. Dacosta NA, Kinare SG. Association of lung carcinoma and tuberculosis. J Postgrad Med. 1991;37(4):185-9.

6. Liang HY, Li XL, Yu XS, Guan P, Yin ZH, He QC, et al. Facts and fiction of the relationship between preexisting tuberculosis and lung cancer risk: a systematic review. Int J Cancer. 2009;125(12):2936-44.

7. Shiels MS, Albanes D, Virtamo J, Engels EA. Increased risk of lung cancer in men with tuberculosis in the alphatocopherol, beta-carotene cancer prevention study. Cancer Epidemiol Biomarkers Prev. 2011;20(4):672-8.
Our case report showed that Tuberculosis and carcinoma can coexist in lung and requires early institution of treatment.The association between these two diseases is important, since both are quite prevalent and have a major impact on public health.

\section{CONCLUSION}

High index of suspicision of coexistence of lung carcinoma and pulmonary tuberculosis should be kept when an old aged patient presents with signs and symptoms of any of these.

\section{ABBREVIATIONS}

HRZE-Isoniazid, Rifampicin,Pyrazinamide,Etambutol DOTS-Directly Observed Treatment Shortterm

TB-Tuberculosis

8. Wu CY, Hu HY, Pu CY, Huang N, Shen HC, Li CP, et al. Pulmonary tuberculosis increases the risk of lung cancer: a population-based cohort study. Cancer. 2011;117(3):618-24.

9. $\mathrm{Yu} \mathrm{YH}$, Liao $\mathrm{CC}, \mathrm{Hsu} \mathrm{WH}$, Chen $\mathrm{HJ}$, Liao $\mathrm{WC}$, Muo $\mathrm{CH}$, et al. Increased lung cancer risk among patients with pulmonary tuberculosis: a population cohort study. J Thorac Oncol. 2011;6(1):32-7.

10. Ballaz S, Mulshine JL. The potential contributions of chronic inflammation to lung carcinogenesis.Clin Lung Cancer. 2003;5(1):46- 62.

11. Coussens LM, Werb Z. Inflammation and cancer. Nature. 2002;420(6917):8607.

12. Engels EA. Inflammation in the development of lung cancer: epidemiological evidence. Expert Rev Anticancer Ther. 2008;8(4):605-15.

13. Rybacka-Chabros B, Må̊"dziuk S, Berger-Lukasiewicz A, DaÅ"ko-MroziÅ"ska M, Milanowski J. The coexistence of tuberculosis infection and lung cancer in patients treated in pulmonary department of Medical Academy in Lublin during last ten years (1990-2000). Folia Histochem Cytobiol. 2001;39 Suppl 2:73-4.

14. Kim HR, Hwang SS, Ro YK, Jeon CH, Ha DY, Park SJ, et al. Solid-organ malignancy as a risk factor for tuberculosis. Respirology. 2008;13(3):413-9. 